\title{
Urinary excretion of ethoxyacetic acid after experimental human exposure to ethylene glycol monoethyl ether
}

\author{
D GROESENEKEN, H VEULEMANS, R MASSCHELEIN
}

From the Laboratorium voor Arbeidshygiëne en -toxicologie, Afdeling Arbeids-en Verzekeringsgeneeskunde, KU Leuven B-3000 Leuven, Belgium

ABSTRACT Ten healthy male subjects were exposed to ethylene glycol monoethyl ether (EGEE) under various conditions of exposure concentration and physical workload and their urinary excretion of ethoxyacetic acid was followed up for $\mathbf{4 2}$ hours. Maximal excretion of ethoxyacetic acid was reached three to four hours after the end of the four hour exposure period. Afterwards, ethoxyacetic acid excretion declined slowly with a biological half life of 21-24 hours. Ethoxyacetic acid excretion increased as the uptake of EGEE increased as a consequence of higher exposure concentration or pulmonary ventilation rate during physical exercise. On average, $23 \cdot 1 \pm 6 \cdot 3 \%$ of EGEE was recovered as ethoxyacetic acid within $\mathbf{4 2}$ hours and the recovery did not change as the uptake of EGEE increased. Quantitative relations between ethoxyacetic acid excretion and EGEE uptake were obtained and the relevance of ethoxyacetic acid excretion as a measure for exposure to EGEE is discussed.

In recent years much effort has been given to the investigation of the metabolism and disposition of ethylene glycol ethers in animals. When $\left[{ }^{14} \mathrm{C}\right]-$ ethylene glycol ethers were given to rats or dogs, $60-80 \%$ was recovered in urine after 48 hours. $^{1-6}$ Furthermore, $10-14 \%$ of the label was recovered as ${ }^{14} \mathrm{CO}_{2}$ in the expired air of treated animals when the label was in the ethanol part of the molecule. ${ }^{1-4}$ When the label was in the alkoxy part, however, only $1-5 \%$ of radioactivity appeared as ${ }^{14} \mathrm{CO}_{2}{ }^{6}$

Methoxyacetic acid was identified as the major urinary metabolite (75-90\%) in rats exposed to ethylene glycol monoethyl ether (EGME). ${ }^{136}$ Analogously, ethylene glycol monobutyl ether (EGBE) was metabolised and excreted mostly in the form of butoxyacetic acid. $^{7}$ On the other hand, two major urinary metabolites were identified in rats and dogs after the administration of the ethyl (EGEE) and isopropyl (EGiPE) ether, respectively, ethoxyacetic acid and isopropoxyacetic acid (45-30\%) and their glycine conjugate $(30-45 \%){ }^{24}$ Both metabolites accounted for approximately $75 \%$ of the administered dose.

Accepted 21 January 1986
Using unlabelled EGEE, however, Jönssen et al estimated the combined excretion of ethoxyacetic acid and the glycine conjugate in rats to be about $30 \%$ of the given dose. ${ }^{8}$ Recently, we could also detect ethoxyacetic acid in the urine of man exposed to $20 \mathrm{mg} / \mathrm{m}^{3}$ EGEE. ${ }^{9}$

All these findings suggest that monitoring the urinary excretion of the alkoxyacetic acids may be a useful indication of human exposure to ethylene glycol ethers. Therefore we have studied the urinary excretion of ethoxyacetic acid in man after exposure to EGEE at various conditions of exposure concentration and physical workload and its relevance as a measure of individual solvent uptake.

\section{Materials and methods}

SUBJECTS AND EXPOSURE CONDITIONS

As described previously, ${ }^{10}$ the experimental group consisted of 10 healthy male subjects (aged 19-28) who were exposed for four hours to various concentrations of EGEE in inspired air, both at rest and during physical exercise. They were randomly assigned into two groups and took part in three experiments according to their group assignment. The 
first group $(n=5)$ was exposed at rest to concentrations of $10 \mathrm{mg} / \mathrm{m}^{3}, 20 \mathrm{mg} / \mathrm{m}^{3}$, and $40 \mathrm{mg} / \mathrm{m}^{3}$ and the second $(\mathrm{n}=5)$ to $20 \mathrm{mg} / \mathrm{m}^{3}$ at rest and during standard physical exercises at $30 \mathrm{~W}$ and $60 \mathrm{~W}$.

To avoid a possible interference with ethoxyacetic acid formation, alcohol consumption was excluded from the evening before the experiment till after the last urine sampling.

\section{SAMPLING PROCEDURES AND ANALYTICAL METHODS}

Samples of inhaled and mixed expired air were taken and analysed as described elsewhere. ${ }^{10}$

Samples of urine were collected just before the exposure period and every hour from the start till the fourth hour after the exposure. The subjects were given seven containers in which to take three two hour collections for the rest of the day and four eight hour collections during the next day. On each sample the density, urinary volume, and creatinine concentration were assessed. Ethoxyacetic acid concentration was determined gaschromatographically as the methylester according to Groeseneken et al. ${ }^{9}$

\section{STATISTICAL ANALYSIS}

Data were analysed using three way analysis of variance with experimental condition, time of follow up, and subjects as main sources of variation. Single and multiple linear regression analysis were used where appropriate.

\section{Results}

TIME COURSE OF ETHOXYACETIC ACID EXCRETION

Before exposure to EGEE, ethoxyacetic acid was

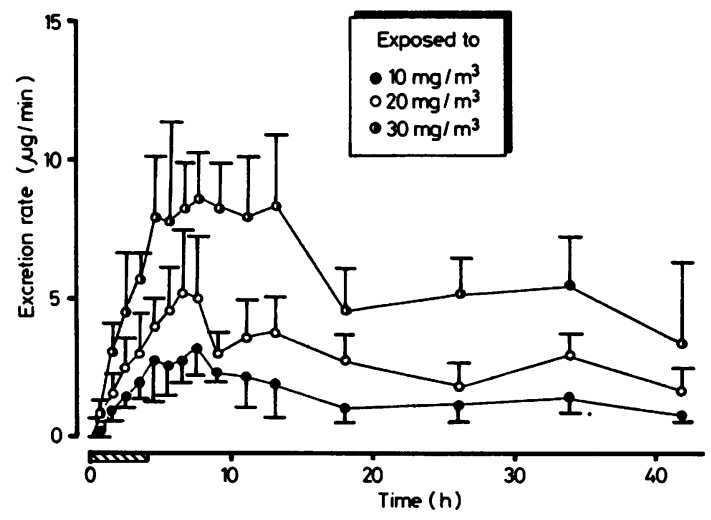

Fig 1 Urinary excretion of ethoxyacetic acid during and after exposure to EGEE at rest. Data are means $\pm S D$ for five subjects. Shaded area indicates exposure period. either not present in the urine or present only at $\overline{\underline{\alpha}}$ concentrations near the detection limit $(\sim 0.07 \mathrm{mg} / \mathrm{l}) . \bar{z}$ During exposure, both at rest and during physical $\stackrel{\mathbb{\Phi}}{\circ}$ exercise, a noticable increase in the rate of excretion $\Rightarrow$ of ethoxyacetic acid was observed from the first hour $\overrightarrow{\vec{s}}$ of the experiment (figs 1 and 2). The rate continued too increase when the exposure was interrupted and흘 reached a maximal level three to four hours after the end of the exposure period. Thereafter a slow $\mathbb{\infty}$ exponential decrease was observed with a biological half life between 21 and 24 hours. Even after $42^{\infty}$ s hours, the excretion rate had not returned to baseline $\vec{O}$ values. A similar time course was obtained when eth- $\vec{\overrightarrow{ }}$ oxyacetic acid excretion was expressed per gram of ${ }_{\sigma}^{\omega}$ creatinine.

\section{EFFECT OF THE EXPOSURE CONDITIONS}

In the resting condition the rate of urinary excretion of ethoxyacetic acid increased $(F=28.8 ; p<0.001)$ क with an increase in exposure to EGEE. When exposed $\vec{r}$ to the same concentration during physical exercise, 음 however, the excretion rate also increased $(F=15 \cdot 0 ;-$ $\mathrm{p}<0.005)$ as the level of work increased. In both $\$$ cases the urinary excretion of ethoxyacetic acido appeared to be clearly related to the rate of uptake of $\frac{\mathbb{D}}{3}$ EGEE, calculated as

$$
\text { uptake rate }(\mu \mathrm{g} / \mathrm{min})=\left(\mathrm{C}_{\mathrm{I}}-\mathrm{C}_{\mathrm{E}}\right) . \stackrel{\mathrm{V}}{\mathrm{E}}
$$

where $\mathrm{C}_{\mathrm{l}}, \mathrm{C}_{\mathrm{E}}(\mu \mathrm{g} / \mathrm{l})$ represent EGEE concentration o̊ñ inspired and expired air and $\mathrm{V}_{\mathrm{E}}(\mathrm{l} / \mathrm{min})$ represents pulmonary ventilation rate. The rate of uptapeo increased for both exposure at rest to increasing EGEE concentrations $(F=80.7 ; p<0.001)$ and foro exposure during physical exercise $(F=113.5 ; \%$

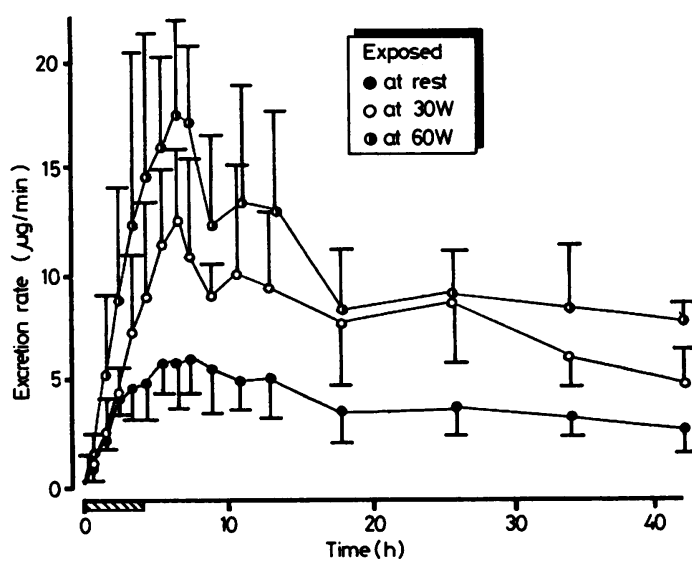

Fig 2 Urinary excretion of ethoxyacetic acid during and after exposure to $20 \mathrm{mg} / \mathrm{m}^{3}$ EGEE during physical exercise. Data are means $\pm S D$ for five subjects. Shaded area indicates exposure period. 
Table 1 Uptake of EGEE and 42 hour excretion of ethoxyacetic acid (EAA). (Data are means $\pm S D$ for five subjects)

\begin{tabular}{|c|c|c|c|}
\hline Experiment & EGEE absorbed (mg) & $\begin{array}{l}\text { EAA excreted in } 42 h \\
\text { (mg-equiv of EGEE) }\end{array}$ & $\%$ of dose absorbed \\
\hline $\begin{array}{l}\text { Group 1: } \\
10 \mathrm{mg} / \mathrm{m}^{3}-0 \mathrm{~W} \\
20 \mathrm{mg} / \mathrm{m}^{3}-0 \mathrm{~W} \\
40 \mathrm{mg} / \mathrm{m}^{3}-0 \mathrm{~W}\end{array}$ & $\begin{array}{l}16.7 \pm 4.2 \\
35.1 \pm 7.6 \\
64.1 \pm 14.5 \\
F=80.7 \\
p<0.001\end{array}$ & $\begin{array}{l}3.5 \pm 0.9 \\
7.4 \pm 0.7 \\
12.2 \pm \pm 2.4 \\
F=48.9 \\
p<0.001\end{array}$ & $\begin{array}{l}21 \cdot 1 \pm 7.5 \\
21.7 \pm 3.9 \\
21.0 \pm 7.8 \\
F=0.3 \\
\text { NS }\end{array}$ \\
\hline $\begin{array}{l}\text { Group 2 } \\
20 \mathrm{mg} / \mathrm{m}^{3}-0 \mathrm{~W} \\
20 \mathrm{mg} / \mathrm{m}^{3}-30 \mathrm{~W} \\
20 \mathrm{mg} / \mathrm{m}^{3}-60 \mathrm{~W}\end{array}$ & $\begin{array}{l}33.3 \pm 8.3 \\
57.0 \pm 11.8 \\
94.4 \pm 13.9 \\
F=176.9 \\
p<0.001\end{array}$ & $\begin{array}{l}8.4 \pm 2.1 \\
16.2 \pm 4.4 \\
21 \cdot 0 \pm 5.9 \\
F=19 \cdot 3 \\
p<0.001\end{array}$ & $\begin{array}{l}25 \cdot 6 \pm 5 \cdot 2 \\
28 \cdot 5 \pm 5 \cdot 5 \\
23 \cdot 5 \pm 5 \cdot 5 \\
F=1 \cdot 5 \\
\text { NS }\end{array}$ \\
\hline
\end{tabular}

$\mathrm{p}<0.001)$, the latter being due to an increased pulmonary ventilation rate $(F=172.7 ; p<0.001)$.

\section{RECOVERY OF ETHOXYACETIC ACID WITHIN 42 HOURS AFTER EXPOSURE}

The total amount of ethoxyacetic acid excreted within 42 hours was calculated by trapezoïdal integration of the excretion curves and expressed as mg-equivalent of EGEE (table 1).

The 42 hour excretion of ethoxyacetic acid increased as the time weighted uptake of EGEE increased $(F=48.9 ; p<0.001$ for the experiments at rest and $F=19.3 ; p<0.001$ for the experiments during physical exercise). Furthermore, this increase corresponded almost exactly to the differences in uptake rates between experiments. This is indicated by the fact that the relative amounts recovered as ethoxyacetic acid did not differ between experiments $(\mathrm{F}=0.3 ; \mathrm{NS}$ for experiments at rest and $\mathrm{F}=1.5 ; \mathrm{NS}$ for experiments during physical exercise). On average $23 \cdot 1 \pm 6 \cdot 3 \%$ of EGEE was excreted as ethoxyacetic acid within 42 hours.

\section{INDIVIDUAL DIFFERENCES IN THE EXCRETION} OF ETHOXYACETIC ACID

A single regression analysis on pooled data was performed to identify the individual factors influencing the excretion of ethoxyacetic acid.

The total amount of ethoxyacetic acid excreted within 42 hours was significantly related to the EGEE concentration in inspired air $(r=0.30 ; p<0.001)$ and uptake rate $(r=0.83 ; p<0.001)$. It was also related to the pulmonary ventilation rate $(r=0.70$; $p<0.001)$ and to oxygen consumption ( $r=0.53$; $\mathrm{p}<0.001)$ during exposure and to the heart rate during $(r=0.78 ; p<0.001)$ and after exposure $(r=0.54$; $\mathrm{p}<0.001)$. Ethoxyacetic acid was negatively related to the subject's height $(r=-0.36$; $p<0.001)$, body weight $(r=-0.20 ; p<0.05)$, and lean body mass $(\mathrm{r}=-0.17 ; \mathrm{p}<0.05)$. No relation was found between ethoxyacetic acid excretion and the subject's body fat content, estimated by the skinfold thickness at four different sites. ${ }^{11}$

In multiple linear regression analysis only the relations $(R=0.99 ; p<0.001)$ between ethoxyacetic acid excretion and EGEE uptake rate $(r=0.73$; $\mathrm{p}<0.001)$, heart rate $(\mathrm{r}=0.58 ; \mathrm{p}<0.001)$, and oxygen consumption $(r=0.22 ; p<0.05)$ during exposure as well as height $(r=-0.43$; $\mathrm{p}<0.001)$ persisted. Respiratory frequency $(r=-0.48$; $\mathrm{p}<0.001$ ) was now found to be also a significant contributing factor to ethoxyacetic acid excretion.

Thus besides the rate of uptake some cardiorespiratory factors which could influence the metabolic rate of EGEE, and some indices of total volume

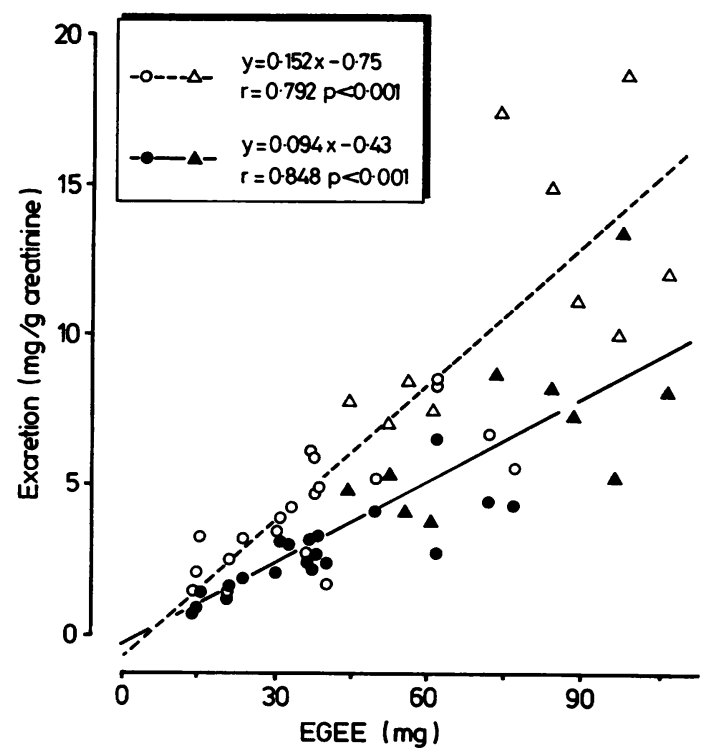

Fig 3 Correlation between time weighted individual uptake of EGEE at rest $(O, O)$ and during physical exercise $(\triangle, \Delta)$, and urinary excretion of ethoxyacetic acid at maximal excretion (open symbols) and next morning (closed symbols). 
Table 2 Urinary concentrations and excretion rates of ethoxyacetic acid as a function of inspired concentration, workload, and time of urine sampling

\begin{tabular}{|c|c|c|c|c|}
\hline \multirow{2}{*}{$\begin{array}{l}\text { Exposure } \\
\text { condition }\end{array}$} & \multirow{2}{*}{$\begin{array}{l}\text { Time after the } \\
\text { end of exposure (h) }\end{array}$} & \multirow{2}{*}{$\begin{array}{l}\text { Concentration* } \\
(\mathrm{mg} / \mathrm{l})\end{array}$} & \multicolumn{2}{|c|}{ Excretion rate expressed as } \\
\hline & & & $\overline{(\mu g / \min )}$ & (mg/g creatinine) \\
\hline$\underset{(n=5)}{10 \mathrm{mg} / \mathrm{m}^{3}}-0 \mathrm{~W}$ & $\begin{array}{c}0 \\
4 \\
18+\end{array}$ & $\begin{array}{l}2.03 \pm 0.61 \\
3.24 \pm 0.95 \\
1.58 \pm 0.56\end{array}$ & $\begin{array}{l}1.99 \pm 0.59 \\
3.19 \pm 0.92 \\
1.55 \pm 0.55\end{array}$ & $\begin{array}{l}1.72 \pm 0.58 \\
2.17 \pm 0.79 \\
1.12 \pm 0.34\end{array}$ \\
\hline$\underset{(\mathrm{n}=10)}{20 \mathrm{mg} / \mathrm{m}^{3}}-0 \mathrm{~W}$ & $\begin{array}{c}0 \\
4 \\
18+\end{array}$ & $\begin{array}{l}3.78 \pm 1.95 \\
6.05 \pm 2.62 \\
3.08 \pm 1 \cdot 11\end{array}$ & $\begin{array}{l}3.87 \pm 1.60 \\
5.52 \pm 2.03 \\
3.13 \pm 0.79\end{array}$ & $\begin{array}{l}3.85 \pm 1.73 \\
4.17 \pm 1.40 \\
2.61 \pm 0.50\end{array}$ \\
\hline$\underset{(\mathrm{n}=5)}{40 \mathrm{mg} / \mathrm{m}^{3}}-0 \mathrm{~W}$ & $\begin{array}{c}0 \\
4 \\
18 \dagger\end{array}$ & $\begin{array}{l}5.71 \pm 0.89 \\
8.76 \pm 1.80 \\
5.81 \pm 1.54\end{array}$ & $\begin{array}{l}5.68 \pm 0.87 \\
8.65 \pm 1.73 \\
5.65 \pm 1.51\end{array}$ & $\begin{array}{l}5.23 \pm 1.67 \\
6.86 \pm 1.48 \\
4.54 \pm 1.36\end{array}$ \\
\hline $\begin{array}{c}20 \mathrm{mg} / \mathrm{m}^{3}-30 \mathrm{~W} \\
(\mathrm{n}=5)\end{array}$ & $\begin{array}{c}0 \\
4 \\
18 \dagger\end{array}$ & $\begin{array}{r}5.48 \pm 2.14 \\
11.83 \pm 5.12 \\
5.68 \pm 2.41\end{array}$ & $\begin{array}{r}7.36 \pm 3.60 \\
10.87 \pm 4.67 \\
6.01 \pm 1.42\end{array}$ & $\begin{array}{l}7.42 \pm 2.84 \\
9.53 \pm 5.06 \\
6.26 \pm 1.92\end{array}$ \\
\hline$\underset{(n=5)}{20 \mathrm{mg} / \mathrm{m}^{3}}-60 \mathrm{~W}$ & $\begin{array}{c}0 \\
4 \\
18 \dagger\end{array}$ & $\begin{array}{r}9.41 \pm 3.90 \\
17.37 \pm 3.66 \\
8.33 \pm 3.41\end{array}$ & $\begin{array}{r}12 \cdot 00 \pm 4 \cdot 15 \\
17 \cdot 13 \pm 3.69 \\
8 \cdot 38 \pm 2.94\end{array}$ & $\begin{array}{r}10.49 \pm 4.18 \\
14.38 \pm 4.63 \\
8.64 \pm 3.05\end{array}$ \\
\hline
\end{tabular}

*Corrected for a mean urine density of 1.024 .

†Morning collection of the next day.

of distribution (height, weight, lean body mass) appeared to be the determinant factors for the excretion of ethoxyacetic acid.

ETHOXYACETIC ACID EXCRETION AS A MEASURE FOR EGEE EXPOSURE

Urinary metabolite levels are usually determined on spot samples taken near the end of a complete workshift. It may be assumed, however, from our experiments that a maximal excretion rate of ethoxyacetic acid will be reached some hours later. Nevertheless, for exposures at rest and during moderate physical exercise, good correlations $(r \geqslant 0.75 ; p<0.001)$ were observed at any time after the exposure period between ethoxyacetic acid excretion ( $\mathrm{mg} / \mathrm{g}$ creatinine) and the time weighted EGEE uptake. This is shown in fig 3 for data at maximal excretion rate and for data from the morning collection from the next day.

Urinary concentration, corrected for a mean urine density of 1.024 , and excretion rates of ethoxyacetic acid are presented in table 2 at three different times after the exposure under the various experimental conditions.

\section{Discussion}

As soon as exposure to EGEE was started, ethoxyacetic acid was excreted in the urine. These results suggest that the metabolism of EGEE in man proceeds primarily by oxidation and are consistent with the biotransformation pathways reported for ethylene glycol monoalkyl ethers in animals. ${ }^{1-7}$ Although the metabolism of EGEE has been studied to some extent, information pertaining to its pharmacokinetics has not been previously reported in man. After an initial rise during exposure, the rate of excre-

tion of ethoxyacetic acid continued to increase afterthe exposure was interrupted and maximal levels weres reached three to four hours after the end of the fouro hour exposure period. Afterwards, the excretion rate declined slowly with a biological half life of $21-24$ hours. This half life is much longer than those reported in animal studies. After a single oral dose ofe $\left[{ }^{14} \mathrm{C}\right]-\mathrm{EGEE}$, radioactivity appeared in the urine $\$ 0 \mathrm{~S}^{\circ}$ rats with a half life of $10-12.5$ hours. ${ }^{4}$ In beagle dogs the radioactivity from $\left[{ }^{14} \mathrm{C}\right]-E G E E$ acetate in blood declined exponentially with an elimination hăls life of eight hours. ${ }^{5}$

Urinary excretion of ethoxyacetic acid increased a the uptake of EGEE through the lungs increased as the result either of higher exposure concentrations o $\overrightarrow{\overrightarrow{0}}$ increased pulmonary ventilation rate during physica $\bar{B}$ work. In addition to the rate of uptake of EGEE other factors may influence the urinary excretion of. ethoxyacetic acid. Since EGEE is most probably metabolised by liver alcohol dehydrogenase, ${ }^{6}$ an enhanced transport to the liver would increase metabo olism and elimination. The positive correlation. between ethoxyacetic acid excretion and heart rate and oxygen consumption, indices of cardiac output support this hypothesis. The negative correlations with height, weight, and lean body mass of the subject suggest that a smaller distribution volume results ir? higher excretion rates of ethoxyacetic acid.

On average, $23 \%$ of inhaled EGEE was recovered as ethoxyacetic acid within 42 hours. No differencos was found between experiments at rest and during physical work. The recovery of ethoxyacetic acid is somewhat lower than in animals. Conjugation of eth oxyacetic acid with glycine has been reported in rats, ${ }^{48}$ and a higher degree of conjugation in man, aș compared with rats, may explain our observation:o 
Attempts to determinate the glycine conjugate of ethoxyacetic acid indirectly by acid hydrolysis, ${ }^{24}$ however, have failed since no increase of ethoxyacetic acid levels were detected even after 17 hours of hydrolysis at $90^{\circ} \mathrm{C}(12.5 \pm 4.1 \mathrm{mg} / 1 v 12.8 \pm 3.4 \mathrm{mg} / 1, \mathrm{t}=0.98$; NS for 15 samples). Other metabolic pathways or disposition routes may be important. Cleaving of the ether linkage and further metabolism of the ethanediol moiety to $\mathrm{CO}_{2}$ has been reported in animals. $^{14}$ Direct respiratory elimination of unchanged EGEE, however, is only a minor disposition route in man since $\leqslant 0.4 \%$ of EGEE is eliminated through the lungs. ${ }^{10}$

The monitoring of ethoxyacetic acid excretion as a measure of exposure to EGEE seems plausible. For a single exposure of four hours, quantitative relations between uptake of EGEE and excretion of ethoxyacetic acid were obtained at any time after the exposure period. Due to the long biological half life observed in man, however, ethoxyacetic acid will not be cleared from the urine the next morning and accumulation of the metabolite may be expected through repetitive exposures. Studies in the field would be necessary to explore the practicability of the method.

We thank Dr W Goossens from the department of haematology for performing the lyophilisations of urine and the haemotological screening tests and Dr W Lissens from the Central Laboratory for performing the liver tests and the urinary creatinine determinations. We also gratefully acknowledge the excellent technical help of Mrs A Veirman, Ms C Jackers, Ms $\mathbf{H}$ Janssens, and Ms A Mannaerts. In addition, we thank Mrs M Rogghe for preparing the manuscript. This work was supported by the Institute of Hygiene and Epidemiology of the Belgian Ministry of Public Health, contract No G/1701/1983-4.
Requests for reprints to: D Groeseneken, Laboratorium voor Arbeidshygiëne en -toxicologie, Provisorium I, Minderbroedersstraat 17, B-3000 Leuven, Belgium.

\section{References}

1 Hutson DH, Pickering BA. The metabolism of isopropyl oxitol in rat and dog. Xenobiotica 1971;1:105-19.

2 Miller RR, Hermann EA, Langvardt PW, McKenna MJ, Schwetz BA. Comparative metabolism and disposition of ethylene glycol monomethyl ether and propylene glycol monomethyl ether in male rats. Toxicol Appl Pharmacol 1983;67: 229-37.

3 Miller RR, Hermann EA, Young JT, Landry TD, Calhoun LL. Ethylene glycol monomethyl ether and propylene glycol monomethyl ether: metabolism, disposition, and subchronic inhalation toxicity studies. Environ Health Perspect 1984;57: 233-9.

4 Cheever KL, Plotnick HB, Richards DE, Weigel WW. Metabolism and excretion of 2-ethoxyethanol in the adult male rat. Environ Health Perspect 1984;57:241-8.

5 Guest D, Hamilton ML, Deisinger PJ, DiVincenzo GD. Pulmonary and percutaneous absorption of 2-propoxyethyl acetate and 2-ethoxyethyl acetate in beagle dogs. Environ Health Perspect 1984;57:177-83.

6 Foster PMD, Creasy DM, Foster JR, Gray TJB. Testicular toxicity produced by ethylene glycol monomethyl and monoethyl ethers in the rat. Environ Health Perspect 1984;57:207-17.

7 Jönsson AK, Steen G. n-Butoxyacetic acid, a urinary metabolite from inhaled n-butoxyethanol (butylcellosolve). Acta Pharmacol Toxicol 1978;42:354-6.

8 Jönsson AK, Pedersen J, Steen G. Ethoxyacetic acid and $N$ ethoxyacetylglycine: metabolites of ethoxyethanol (ethylcellosolve) in rats. Acta Pharmacol Toxicol 1982;50:358-62.

9 Groeseneken D, Van Vlem E, Veulemans H, Masschelein R. Gaschromatographic determination of methoxyacetic and ethoxyacetic acid in urine. $\mathrm{Br} \mathrm{J}$ Ind Med 1986;43:62-5.

10 Groeseneken D, Veulemans H, Masschelein R. Respiratory uptake and elimination of ethylene glycol monoethyl ether after experimental human exposure. $\mathrm{Br} J$ Ind $\mathrm{Med}$ 1986;43:544-9.

11 Durnin JVGA, Womersley J. Body fat assessed from total body density and its estimation from skinfold thickness: measurements on 481 men and women aged from 16 to 72 years. Br J Nutr 1974;32:77-97. 